\title{
A novel inducible acute hyperglycemia mouse model for assessing 6-KTP
}

\author{
JINRUI HU, XIA ZHONG, XIAOPING YANG, HONGJIAN LI and YANHONG RAN \\ College of Life Science and Technology, Jinan University, Guangzhou, Guangdong 510632, P.R. China
}

Received November 30, 2018; Accepted June 21, 2019

DOI: $10.3892 /$ br.2019.1228

\begin{abstract}
The aim of the present study was to establish a mouse model of acute hyperglycemia, which may be utilized to detect the glucose concentration-dependent hypoglycemic activity of the glucagon-like peptide-1 derivative, 6-KTP. The results demonstrated that the first $30 \mathrm{~min}$ following the intraperitoneal injection of $2 \mathrm{~g} / \mathrm{kg}$ glucose into C $57 \mathrm{BL} / 6 \mathrm{~J}$ mice was the optimum time for assessing the hypoglycemic activity of potential therapeutic methods for diabetes. There was a linear association between the dose of 6-KTP and hypoglycemic activity between 0.2 and $1.2 \mathrm{mg} / \mathrm{kg}$. The resulting model may serve as template for developing cost-effective in vivo models to test similar therapeutics.
\end{abstract}

\section{Introduction}

Diabetes mellitus is a major health concern, with an estimated 300 million patients diagnosed globally, and with type 2 diabetes mellitus (T2DM) accounting for $>90 \%$ of all cases (1). Glucagon like peptide-1 (GLP-1) derivatives in combination with first-line therapeutics are the preferred regimen for the treatment for patients with T2DM due to the promotion of $\beta$-cell proliferation and the efficacy of non-violent hypoglycemia (2). The half-life of biological GLP-1 is $<4 \mathrm{~min}$, as it is degraded in the plasma by dipeptidyl-peptidase-IV (DPP-IV) (3). Prolonging the half-life of GLP-1 or its derivatives has attracted a notable amount of research attention, particularly GLP-1 receptor agonists, due to their short half-life and the functional properties of GLP-1 receptor activation, including the inhibition of glucagon secretion and the stimulation of insulin secretion, each in a glucose-dependent manner (3). The current GLP-1 derivative strategy includes the modification of residues required for degradation by DPP-IV

Correspondence to: Professor Hongjian Li or Dr Yanhong Ran, College of Life Science and Technology, Jinan University, 601 Whampoa Road West, Guangzhou, Guangdong 510632, P.R. China

E-mail: tlihj@jnu.edu.cn

E-mail:tranyh@jnu.edu.cn

Key words: glucagon-like peptide-1, blood glucose, acute hyperglycemia mouse model, type 2 diabetes therapeutics and structural modifications (4,5). For example, arginine (34th residue) in liraglutide is replaced by lysine, and the addition of a 16-carbon fatty acid chain on the 24th lysine residue may abrogate DPP-IV-mediated degradation, thereby prolonging its half-life (6).

GLP-1 is secreted in response to increasing blood glucose levels and serves to reduce the glucose concentration (7). At present, the majority of studies on this have utilized a T2DM $\mathrm{db} / \mathrm{db}$ or ob/ob model mice with their leptin receptor gene or leptin gene knocked out, in order to determine the efficacy of GLP-1-derived therapeutics in vivo $(8,9)$. Knockout T2DM mice are costly, and the construction cycle of these mice may be time-consuming and, thus, not suitable for higher-throughput identification of potential therapeutic methods.

The acute hyperglycemia mouse model refers to a model of instant hyperglycemia incited by an intraperitoneal injection of glucose (IPG) in fasting healthy mice. The phase of instant hyperglycemia in the mouse occurs prior to the first phase of insulin secretion, typically $30-60 \mathrm{~min}$ following IPG, which is subsequently followed by the slower second phase of insulin secretion when normoglycemia is attained (10). Prior to the first phase of insulin secretion, normal mice injected intraperitoneally with glucose are in a state of hyperglycemia; however, physiologically, the mice will attempt to maintain a high blood glucose level until the hyperglycemic blood is detected (10).

A GLP-1 receptor agonist drug, 6-KTP, was utilized in the present study as described previously (11). The GLP-1 derivative 6-KTP consists of an albumin-binding domain (ABD), a protease-cleavable linker (LK) and native GLP-1 (7-37), and is formed by the covalent conjugation of GLP-1 with albumin mediated by thrombin and DPP-IV proteins present in the blood (11).

The reaction time for the first phase of insulin secretion varies with different strains of mice (12). The period within which 6-KTP exerts its hypoglycemic effect should be determined in the acute hyperglycemic period prior to the first phase of insulin and GLP-1 secretion. Therefore, the best-suited mouse model of acute hyperglycemia should be determined first.

The blood glucose levels in acute hyperglycemia mice are relative to the glucose quantity administered. Acute blood glucose levels may exceed the upper limit of a blood glucose meter $(33.2 \mathrm{mmol} / \mathrm{l})$ if the glucose quantity administered is too high, and too low a quantity of glucose may result in an insufficient or lack of initiation of a hyperglycemic response 
in the mouse model (13). Therefore, the determination of an optimum glucose quantity for IPG is required.

The hypoglycemic effect of 6-KTP is exerted in a glucose-dependent manner. 6-KTP does not initiate a glucose-lowering mechanism if the blood glucose level lies within the physiological range, particularly if the administration of 6-KTP occurs too soon following IPG (11). However, if 6 -KTP release is overly delayed, it may overlap with the first phase of insulin secretion. Therefore, the optimum time point of 6-KTP activity must be determined, and should hypothetically lie in the time frame prior to the first phase of insulin secretion (11).

The present study aimed to determine the ideal mouse model for acute hyperglycemia, the optimum glucose quantity and the optimum time point for the injection of 6-KTP.

\section{Materials and methods}

Intraperitoneal glucose tolerance test (IPGTT). Male KM and male C57BL/6J mice (4-6 weeks old, average of $20 \mathrm{~g}$ per mouse, a total of 24 mice) were purchased from the Guangdong Medical Laboratory Animal Center (Guangzhou, China). The mice were fed commercial mouse food (finely ground, autoclaved, low-fat diet) and housed under controlled conditions $\left(\sim 22^{\circ} \mathrm{C}\right.$ and $45-55 \%$ humidity, with a 12/12-h light/dark cycle) for the entire experiment duration. All mice ate and drank freely. All in vivo experiments were ethically approved by The Jinan University Ethics Committee of Animal Welfare (Guangdong, China).

Following an overnight fast (16 h), each animal was injected intraperitoneally with glucose $(50 \%$ glucose solution, $2 \mathrm{~g} / \mathrm{kg}$ body weight). Blood samples were collected from the tail vein following $0,5,10,15,20,30,60,120$ and $180 \mathrm{~min}(\mathrm{n}=8$ per mouse model). Blood glucose concentrations were measured using OneTouch Ultra (Johnson \& Johnson, New Brunswick, NJ, USA).

6-KTP was obtained from The Laboratory of Biochemistry and Molecular Biology, Jinan University (Guangdong, China). 6-KTP consists of three functional domains, an ABD (amino acid sequence, LPHSHRAHSLPP), a protease cleavable linker (LK; amino acid sequence, FNPRKTP) and bioactive GLP-1.

Intraperitoneal glucose injection. IPGTT was performed on male $\mathrm{C} 57 \mathrm{BL} / 6 \mathrm{~J}$ mice ( $\mathrm{n}=8$ per glucose mouse model) with a glucose dose of $0,0.5,2.0$ and $4.0 \mathrm{~g} / \mathrm{kg}$ body weight. The group of $0 \mathrm{~g} / \mathrm{kg}$ glucose dose was injected with PBS. Blood samples for glucose testing were collected from the tail vein.

Injection of 6-KTP. Acute hyperglycemic male C57BL/6J mice ( $n=8$ per 6 -KTP mouse model) were subcutaneously injected with $0.2,0.3,0.6,0.9,1.2,1.5$ and $1.8 \mathrm{mg} / \mathrm{kg} 6-\mathrm{KTP}$. Blood samples for measuring the blood glucose concentration were collected from the tail vein at 0,10 and $30 \mathrm{~min}$.

Male C57BL/6J mice ( $\mathrm{n}=8$ per mouse model) were subsequently injected with $6-\mathrm{KTP}(1.8 \mathrm{mg} / \mathrm{kg}$ body weight) at 60 , 30 and 0 min prior to IPG. Blood samples for measuring the blood glucose concentration were collected from the tail vein at 0,10 and $30 \mathrm{~min}$.

Acute hyperglycemic male $\mathrm{C} 57 \mathrm{BL} / 6 \mathrm{~J}$ mice $(\mathrm{n}=8$ per $6-\mathrm{KTP}$ mouse model) were subcutaneously injected with $0.25,0.5$,
0.75 and $1 \mathrm{mg} / \mathrm{kg} 6-\mathrm{KTP}$ to determine the association between the 6-KTP dose and the functional effects on blood glucose concentration. Blood samples for measuring the blood glucose concentration were collected from the tail vein at 0,10 and $30 \mathrm{~min}$

Definition of 6-KTP hypoglycemic activity in the acute hyperglycemia mouse model. The 6-KTP hypoglycemic activity unit was defined as follows: i) A unit of 6-KTP hypoglycemic activity (U), $\Delta$ area under the curve (AUC) $)_{0-30 \text { min }}$ for $6-\mathrm{KTP}$ per $100 \mathrm{mmol} / 1 \mathrm{~min}^{-1}$ was defined as one unit in acute hyperglycemia mice; ii) the specific activity of $6-\mathrm{KTP}(\mathrm{U} / \mu \mathrm{g})$, the number of units of hypoglycemic activity per $1 \mu \mathrm{g} 6-\mathrm{KTP}$ in the acute hyperglycemia mouse model.

The conditions for defining a 6-KTP hypoglycemic activity unit were as follows: i) 4-6 week-old male C57BL/6J mice following $16 \mathrm{~h}$ fasting; ii) subcutaneous injection with $100 \mu 16-K T P$ or PBS and a simultaneous intraperitoneal injection of $100 \mu \mathrm{l}$ glucose solution at a concentration of $0.4 \mathrm{~g} / \mathrm{ml}$; iii) blood samples for blood glucose detection were collected from the tail vein at 0,10 and $30 \mathrm{~min}$.

Statistical analysis. All data were expressed as the mean \pm standard error of the mean. Statistical significance was determined using a Student's t-test for comparison between two groups, or a one- or two-way analysis of variance for comparisons between multiple groups, as appropriate, followed by a Student-Newman-Keuls post hoc test. All statistical analyses were performed using GraphPad Prism 6 and SPSS (GraphPad Software, Inc., La Jolla, CA, USA). P $<0.05$ was considered to indicate a statistically significant difference. $\mathrm{AUC}_{0-30 \mathrm{~min}}$ was calculated using GraphPad Prism 6.

\section{Results}

C57BL/6J mice are the best suited strain for constructing an acute hyperglycemia mouse model. Acute hyperglycemia in mice was induced by an IPG and induced insulin secretion within $30 \mathrm{~min}$ (Fig. 1). Different strains of mice exhibit varying rates and time frames of increased insulin secretion following IPG (9). The C57BL/6J and KM mice, each of which are widely used in pharmacological research due to the low cost of attaining and maintaining these strains $(14,15)$, were assessed for their suitability for an acute hyperglycemia mouse model following IPG. There was no significant difference between the blood glucose levels following the first 15 and 30 min of IPG when compared with the same strain at each time point $(\mathrm{P}<0.05$; Table $\mathrm{I})$, although the blood glucose levels were significantly higher in the C57BL/6J strain compared with KM mice following 15 and 30 min of IPG $(\mathrm{P}<0.001$; Fig. 1). Therefore, the C57BL/6J strain was selected for the subsequent generation of an acute hyperglycemia mouse model.

IPG with $2 \mathrm{~g} / \mathrm{kg}$ glucose is the optimum dose for an acute hyperglycemia mouse model. The optimum dose of glucose for the acute hyperglycemia mouse model was determined by injecting mice with four different doses of glucose. The optimum concentration should ideally not exceed the limits of detection by conventional blood glucose meters, but should 
Table I. Blood glucose concentration of C57BL/6J and KM mice at 15 and $30 \mathrm{~min}$ following an intraperitoneal injection of glucose.

\begin{tabular}{llrr}
\hline Mouse strain (time) & Blood glucose concentration, mM & SEM & P-value \\
\hline C57BL/6J (15 min) & 26.97 & 0.61 & 0.183 \\
KM (15 min) & 17.8 & 0.74 & 0.173 \\
C57BL/6J (30 min) & 22.18 & 0.81 & 0.377 \\
KM (30 min) & 14.12 & 0.65 & 0.344 \\
\hline
\end{tabular}

SEM, standard error of the mean.

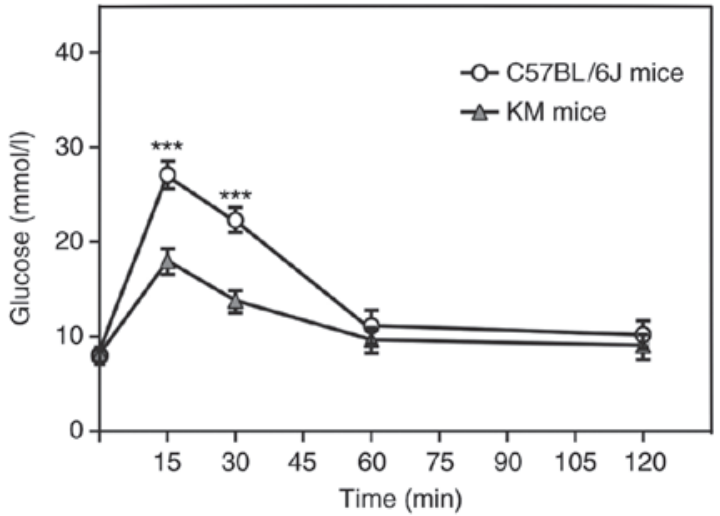

Figure 1. Blood glucose concentration following intraperitoneal injection of glucose in C57BL/6J and KM mice. ${ }^{* * *} \mathrm{P}<0.001$ vs. KM mice.

increase the blood glucose concentration sufficiently to induce a hyperglycemic response. In mice injected with $0.5 \mathrm{~g} / \mathrm{kg}$ glucose, the glucose level only differed significantly compared with that in the control group subsequent to $15 \mathrm{~min}$, and was not sustained $(\mathrm{P}<0.05$; Fig. 2$)$; thus, it was deemed unsuitable. In mice treated with $4 \mathrm{~g} / \mathrm{kg}$ glucose, the blood glucose level approached (and possibly exceeded) the upper limit of the measuring equipment (Fig. 2). The peak glucose level in the group injected with $2 \mathrm{~g} / \mathrm{kg}$ was sufficiently high enough to induce a significant hyperglycemic response compared with the control group, which was maintained for $\geq 30 \mathrm{~min}$, whilst being measurable using the available equipment $(\mathrm{P}<0.001$; Fig. 2).

Injection of 6-KTP at $0 \mathrm{~h}$ is the optimum time point for a maximal hypoglycemic effect. The timing of a subcutaneous injection of 6-KTP should be such that a maximal hypoglycemic effect is initiated prior to first-phase insulin secretion. Injection of 6-KTP at $0 \mathrm{~h}$ was determined to be the optimum time point for 6-KTP to exert its effects, with a significant difference in blood glucose compared with the placebo group $(\mathrm{P}<0.001 ;$ Fig 3$)$. All mice were injected with $2 \mathrm{~g} / \mathrm{kg}$ glucose.

Dose-effect association between 6-KTP and hypoglycemic activity. The $\mathrm{AUC}_{0-30 \text { min }}$ revealed a linear association between the 6-KTP dose and hypoglycemic activity (Table II). Between 0.2 and $1.2 \mathrm{mg} / \mathrm{kg} 6-\mathrm{KTP}$, the linear regression equation was $\mathrm{y}=100.2+234.9 \mathrm{x}$, with an $\mathrm{r}^{2}$ value of 0.9705 (Fig. 4).

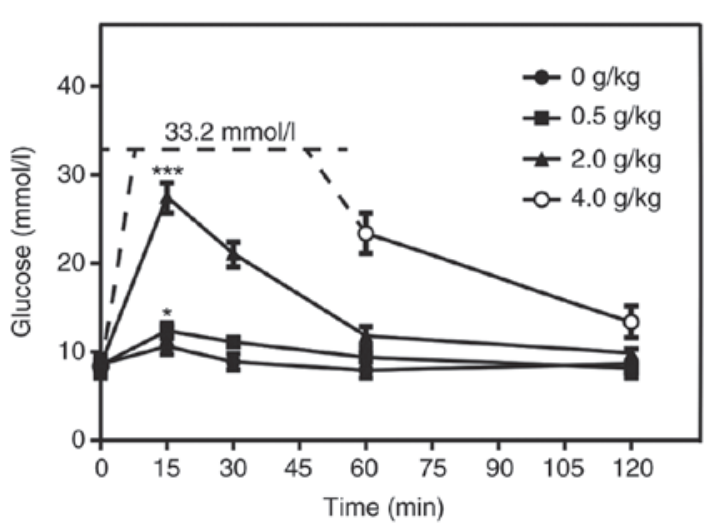

Figure 2. Blood glucose concentration following intraperitoneal injection at a range of glucose doses. ${ }^{*} \mathrm{P}<0.05$ and ${ }^{* * * *} \mathrm{P}<0.001$ vs. the $0 \mathrm{~g} / \mathrm{kg}$ group. Dashed line, limit of detection.

The quantitative association between 6-KTP dose and the functional effect on blood glucose levels was verified by using different 6-KTP doses. The recovery was calculated as described previously (16) for the different doses of 6-KTP, and was quantified by the equation $\leq 100 \pm 15 \%$ (between 0.2 and $1.2 \mathrm{mg} / \mathrm{kg}$ 6-KTP; Table III).

\section{Discussion}

In the present study, an acute hyperglycemic C57BL/6J mouse model was developed. An intraperitoneal injection of $2 \mathrm{~g} / \mathrm{kg}$ glucose alongside an injection of 6-KTP was used to determine the blood glucose-lowering effect of 6-KTP at various concentrations. The results demonstrated a linear association between 6-KTP dose and hypoglycemic activity. An equation for calculating the effect of each 6-KTP dose was developed based on these results.

At present, potential therapeutic methods for T2DM are primarily tested for biological activity using a mouse model of T2DM, but this method has certain disadvantages. The low success rate of constructing a mouse model of T2DM is likely to result in the mice succumbing to mortality or low blood glucose in mice $(17,18)$. Meanwhile, ordering T2DM mice is costly. A rapid detection method for measuring the activity of GLP-1 derivatives over a period of $30 \mathrm{~min}$ was established in the present study. The acute hyperglycemic mouse model was readily inducible by an intraperitoneal injection of $2 \mathrm{~g} / \mathrm{kg}$ glucose solution into fasting C57BL/6J mice. The acute 
Table II. $\triangle \mathrm{AUC}_{0-30 \text { min }}$ of different doses of 6-KTP in the acute hyperglycemia C57BL/6J mouse model.

6-KTP dose, $\mathrm{mg} / \mathrm{kg}$

\begin{tabular}{|c|c|c|c|c|c|c|c|c|}
\hline $\operatorname{AUC}\left(\mathrm{mmol} / 1 \mathrm{~min}^{-1}\right)$ & PBS & 0.2 & 0.3 & 0.6 & 0.9 & 1.2 & 1.5 & 1.8 \\
\hline${ }^{\mathrm{a}} \Delta \mathrm{AUC}_{0-30 \mathrm{~min}}$ & 0 & $126.6 \pm 48.5$ & $179.2 \pm 49.6$ & $255.8 \pm 25.1$ & $325.2 \pm 10.3$ & $365.8 \pm 22.5$ & $357.8 \pm 15.8$ & $370.7 \pm 17.8$ \\
\hline
\end{tabular}

${ }^{\mathrm{a}} \Delta \mathrm{AUC}_{0-30 \mathrm{~min}}=\mathrm{AUC}_{0-30 \text { min }}$ of the PBS group- $\mathrm{AUC}_{0-30 \text { min }}$ of the respective 6-KTP dose. AUC, area under the curve; PBS, phosphate buffered saline.

Table III. Calculated and experimental values of $\Delta \mathrm{AUC}_{0-30 \min }$ values of different 6-KTP doses.

\begin{tabular}{lccc}
\hline Dose of 6-KTP, $\mathrm{mg} / \mathrm{kg}$ & Experimental value, $\mathrm{mmol} / \mathrm{l} \mathrm{min} \mathrm{m}^{-1}$ & Calculated value, mmol/1 min ${ }^{-1}$ & Recovery, $\%$ \\
\hline 0.25 & 147.6 & 158.9 & 107.7 \\
0.5 & 193.7 & 217.7 & 89 \\
0.75 & 256.2 & 276.4 & 92.7 \\
1 & 322.4 & 335.1 & 96.2 \\
\hline
\end{tabular}

$\Delta \mathrm{AUC}_{0-30 \mathrm{~min}}=\mathrm{AUC}_{0-30 \mathrm{~min}}$ of the phosphate buffered saline group- $\mathrm{AUC}_{0-30 \text { min }}$ of the respective 6-KTP dose. AUC, area under the curve.
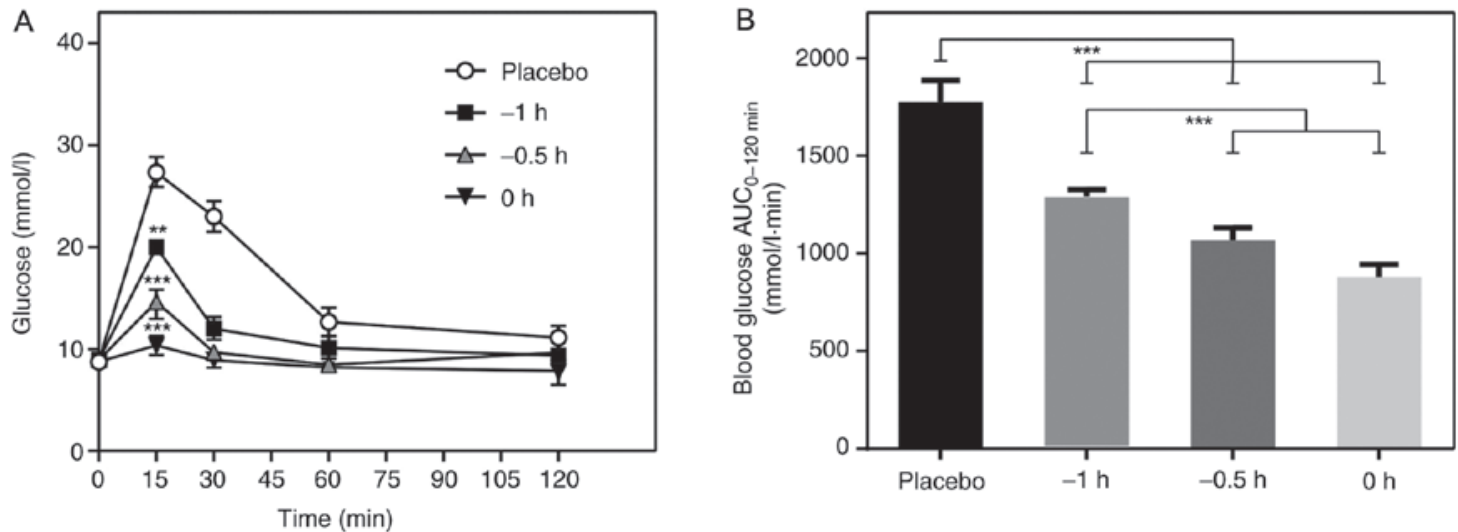

Figure 3. Blood glucose concentration following injection of 6-KTP at varying time points prior to the administration of $2 \mathrm{~g} / \mathrm{kg}$ glucose. (A) Injection of 6-KTP at $0 \mathrm{~h}$ prior to a glucose injection resulted in the largest decrease in blood glucose levels in the first $30 \mathrm{~min}$. ${ }^{* * *} \mathrm{P}<0.01$ and ${ }^{* * *} \mathrm{P}<0.001 \mathrm{vs}$. placebo. (B) Total blood glucose levels in the first $30 \mathrm{~min}$ from (A). Injection of 6-KTP at $0 \mathrm{~h}$ resulted in the largest decrease in blood glucose over the first $30 \mathrm{~min} .{ }^{* * *} \mathrm{P}<0.001 \mathrm{with}$ comparisons shown by lines. The AUC value in (B) was calculated between 0-30 min from (A). AUC, area under the curve.

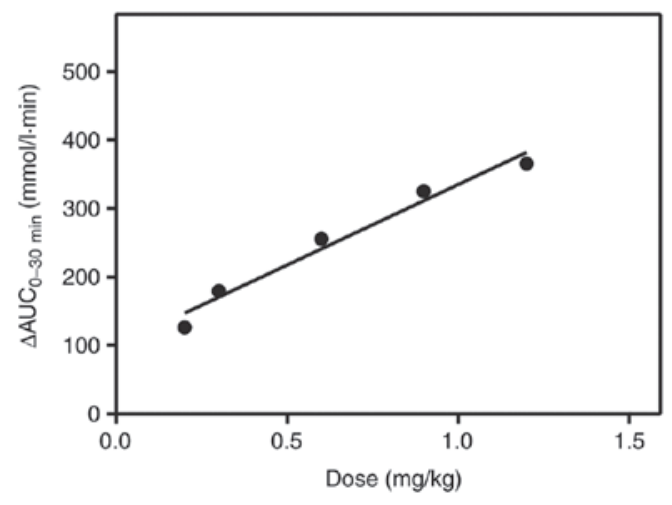

Figure 4. Standard curve of the dose-effect association of 6-KTP with blood glucose $\triangle \mathrm{AUC}_{0-30 \mathrm{~min}}$ values. $\triangle \mathrm{AUC}_{0-30 \mathrm{~min}}=\mathrm{AUC}_{0-30 \mathrm{~min}}$ of the phosphate buffered saline group- $\mathrm{AUC}_{0-30 \text { min }}$ of the respective 6-KTP dose. AUC, area under the curve. hyperglycemic mouse model may be used for pharmacodynamic studies in the early stages of drug screening, shortening the drug screening cycle. At present, a 6-KTP-specific pharmaceutical formulation has been developed, and the acute hyperglycemic mouse model may be used to verify whether the formulation will affect the biological activity of 6-KTP by this rapid testing method.

In the present study, 6-KTP was prepared strictly in aseptic conditions. Subsequent to the completion of the test, the mice were in good health and revealed no notable side effects although no toxicology test was performed on the mice. Toxicology tests examining the impact of 6-KTP in mice will be performed in subsequent studies.

In conclusion, a rapid detection method for GLP-1 derivatives to lower blood glucose levels was established. This method has the advantages of rapid detection and low cost, and 
may serve as a template to develop mouse models for other similar therapeutics.

\section{Acknowledgements}

Not applicable.

\section{Funding}

The present study was funded by The National Major Scientific and Technological Special Project for 'Significant New Drugs Development' during the Twelfth Five-year Plan Period (grant no. 2013ZX09103003-018) and The National Natural Science Foundation of China (grant no. 31500099).

\section{Availability of data and materials}

The datasets used and/or analyzed during the present study are available from the corresponding author on reasonable request.

\section{Authors' contributions}

$\mathrm{JH}$ and $\mathrm{XZ}$ contributed to the design of the study and to the acquisition and interpretation of the data. XY, HL and YR drafted the manuscript and revised it for intellectual content. All authors read and approved the final version of the manuscript for publication.

\section{Ethics approval and consent to participate}

All in vivo experiments performed in the present study were ethically approved by The Jinan University Ethics Committee of Animal Welfare (Guangdong, China).

\section{Patient consent for publication}

Not applicable.

\section{Competing interests}

The authors declare that they have no competing interests.

\section{References}

1. Piya MK, Tahrani AA and Barnett AH: Emerging treatment options for type 2 diabetes. Br J Clin Pharmacol 70: 631-644, 2010.

2. Drucker DJ and Nauck MA: The incretin system: Glucagon-like peptide-1 receptor agonists and dipeptidyl peptidase-4 inhibitors in type 2 diabetes. Lancet 368: 1696-1705, 2006.

3. Bo A: GLP-1 for type 2 diabetes. Exp Cell Res 317: 1239-1245, 2011.

4. Malik DK, Baboota S, Ahuja A, Hasan S and Ali J: Recent advances in protein and peptide drug delivery systems. Curr Drug Deliv 4: 141-151, 2007.

5. Pawar R, Ben-Ari A and Domb AJ: Protein and peptide parenteral controlled delivery. Expert Opin Biol Ther 4: 1203-1212, 2004.

6. Perry CM: Liraglutide. Drugs 71: 2347-2373, 2011.

7. Dunning BE, Foley JE and Ahrén B: Alpha cell function in health and disease: Influence of glucagon-like peptide-1. Diabetologia 48: 1700-1713, 2005.

8. Wang Q and Brubaker PL: Glucagon-like peptide-1 treatment delays the onset of diabetes in 8 week-old $\mathrm{db} / \mathrm{db}$ mice. Diabetologia 45: 1263-1273, 2002.

9. Ding X, Saxena NK, Lin S, Gupta NA and Anania FA: Exendin-4, a glucagon-like protein-1 (GLP-1) receptor agonist, reverses hepatic steatosis in ob/ob mice. Hepatology 43: 173-181, 2006.

10. Del Prato S and Tiengo A: The importance of first-phase insulin secretion: Implications for the therapy of type 2 diabetes mellitus. Diabetes Metab Res Rev 17: 164-174, 2001.

11. Li HJ, Ma Y, Chen Y, Sang Y, Zhou T, Qiu M, Huang X, Zhou C and Su Z: A protease-based strategy for the controlled release of therapeutic peptides. Angew Chem Int Ed Engl 49 :4930-4933, 2010.

12. Berglund O: Different dynamics of insulin secretion in the perfused pancreas of mouse and rat. Acta Endocrinol (Copenh) 93: 54, 1980.

13. Voss EM, Bina DM, Mcneil LAD, Johnson ML and Cembrowski GS: Determining acceptability of blood glucose meters: Evaluating a blood glucose testing system. Lab Med 27: 679-682, 1996.

14. Collins S, Martin TL, Surwit RS and Robidoux J: Genetic vulnerability to diet-induced obesity in the C57BL/6J mouse: Physiological and molecular characteristics. Physiol Behav 81: 243-248, 2004

15. Pan Z, Zhu Z, Wang H, Zhou W, Yao J and Xu Z: Study of the biological characteristics of Sibp: KM mouse. Acta Laboratorium Animalisentia Sinica 13: 1-6, 1995.

16. Pharmacopoeia of the People's Republic of China: Volume 4, Chapter 9101. Chemical Industry Press, Beijing, pp374-375, 2015.

17. Lenzen S: The mechanisms of alloxan-and streptozotocin-induced diabetes. Diabetologia 51: 216-226, 2008.

18. Ramanadham S, Doroudian A and McNeill JH: Myocardial and metabolic abnormalities in streptozotocin-diabetic Wistar and Wistar-Kyoto rats. Can J Cardiol 6: 75-82, 1990. 